\title{
Pertunjukan Teater Karo Hip Hop Kontemporer KAI
}

\author{
Silvia Anggreni Purba \\ Jurusan Teater, Fakultas Seni Pertunjukan, Institut Seni Indonesia Yogyakarta
}

\begin{abstract}
ABSTRAK
Pertunjukan ini berawal dari sebuah ide untuk mengkolaborasikan tradisi Karo dengan budaya populer. Dengan cara seperti ini pertunjukan bisa dinikmati tanpa batasan bahasa dan budaya. Proses menggabungkan dua budaya yang berbeda merupakan bentuk budaya hibrida dan terjadi akibat proses globalisasi. Melalui proses pengendapan pengamatan dan kesan yang kuat, pertunjukan ini dibawa ke dalam bentuk Hip Hop. Pertunjukan ini merupakan bagian dari sebuah tragedi modern dengan karakter destruktif, mengeksplorasi emosi dan menyampaikannya kepada penonton. Eksplorasi budaya Karo dan tari Hip Hop sebagai bahasa simbol mampu memperkuat kata-kata. Gerak tidak diungkapkan dengan kata lisan tetapi disajikan melalui gerak tari Hip Hop. Penafsiran legenda dan teks ke dalam gerak, melalui proses pelatihan di laboratorium sebagai proses pencarian dan eksperimentasi diwujudkan dengan mempertimbangkan unsur-unsur dasar dari Hip Hop, unsur budaya Karo dan tontonan. Karo Hip Hop diharapkan menjadi bentuk estetika teater modern yang diinginkan tanpa kehilangan tradisi.
\end{abstract}

Kata kunci: Tari Karo kontemporer, Hip-hop, budaya hibrida

\begin{abstract}
Pertunjukan Teater Karo Hip Hop Kontemporer KAI. The performance of Karo Theater collaborated with Hip Hop stems from a simple idea to collaborate Karo cultural traditions with popular culture. The performances can be enjoyed without having limitation on the language and culture. The process of combining two different cultures is a form of hybrid culture, and it may occur due to the globalization process. Through the process of deposition of the observations and strong impression, this performance is then brought into the form of Hip Hop as a preferred form which is energetic, personal and global. This performance is part of a modern tragedy with its destructive character which has explored the emotion and has presented it to the audiences. The exploration of Karo cultural tradition and Hip Hop dance as a language of symbols is able to reinforce words. The movement is not revealed by the verbal phrase but is presented through the movement of Hip Hop dance. The interpretation of the legend and texts into movement is carried out through the training process at the laboratory as a searching process and experiment, and afterward can be realized by considering the basic elements of Hip Hop, Karo cultural elements and performance. Karo Hip Hop Theatre is expected to become a preferred aesthetic form of a modern theater without losing its tradition form.
\end{abstract}

Keyword: a contemporary Karo theater, Hip Hop, hybrid culture.

\section{Pendahuluan}

Hakekat sebuah pertunjukan teater ditangan seorang sutradara adalah mencoba merealisasikan gagasan, ide dan hasratnya ke hadapan penonton terutama sutradara yang juga bertindak sebagai penulis naskah. Penciptaan teater kali ini pun tidak terlepas dari tujuan tersebut, yaitu hasrat untuk mementaskan sebuah pertunjukan berdasarkan tradisi budaya kekinian. Tradisi dan budaya merupakan sumber inspirasi yang tidak ada habisnya untuk terus digali, dipahami dan dibaca kembali melalui mata seorang seniman. Inspirasi hadir dari upacara ritual, dongeng, legenda, mitos, tarian, nyanyian, serta adat istiadat yang menjadi pegangan hidup.
Sumber inspirasi penciptaan kali ini adalah legenda dari Tanah Karo, Sumatera Utara, legenda 'Guru Pertawar Reme'. Legenda ini cukup terkenal melalui beberapa tempat peninggalan berupa tempat ritual, pemandian air panas, serta kuburan sang guru. Tahun 2006, pementasan teater dengan judul Guru Kandibata merupakan karya pertama penulis yang digarap berdasarkan legenda tersebut. Berpijak dari karya sebelumnya penulis mencoba untuk mengembangkannya, mencari data-data, informasi, mendatangi tempat-tempat yang saling terhubung, hal-hal yang masih dipercayai atau dilakukan berkaitan seputar legenda tersebut, bahkan cerita-cerita mistis yang melingkupinya. Selain itu sumber ide lain yang menjadi pijakan adalah segala sesuatu yang berkaitan dengan

1 Alamat korespondensi: Jurusan Teater, Fakultas Seni Pertunjukan. ISI Yogyakarta. Jalan Parangtritis Km 6,5 Sewon, Yogyakarta. Telepon: 0274-384108. 
kebudayaan yang ada di Tanah Karo. Kebudayaan merupakan sistem mengenai konsepsi-konsepsi yang diwariskan dalam bentuk simbolik, yang dengan cara ini manusia dapat berkomunikasi, melestarikan, dan mengembangkan pengetahuan dan sikapnya terhadap kehidupan (Geertz, dalam Abdullah, 2010: 1). Orang Karo memiliki rakut si teluldaliken si telu sebagai konsepsi yang diwariskan dan mengikat orang Karo dalam menjalankan kehidupan. Konsepsi ini merupakan bahasa tutur yang diajarkan melalui praktik kehidupan sehari-hari. Henry Guntur Tarigan pernah menuliskannya dalam buku Antusen Bilangen ibas Kalak Karo Makna Bilangan pada Masyarakat Karo, sbb:

"Telu dalikanna-dalikan si telu-labo lit empat, seri ganjangna seri lapatna. Lapat ia labo ku pudi, tapi lapat ku lebe nge, sempa tenggur takal, seri ganjangna; belinna maka banci sibelin-belinen, tapi ganjangna la banci la seri, perbahan adi siganjang-ganjangen ia, adi sedang ia, la banci tetap kudin tah pe kudin perdakanen ras sidebanna ibas dalikan ibas dapur e. Jadi e maka ningen daliken si telu, rakut si telu nina ibas adat kalak Karo, em kap: ANAKBERU- SENINA-KALIMBU$B U$ " (Tarigan, 1994: 8).

Artinya: tiga tungkunya-tungku nan tiga-tidak ada yang empat, sama tingginya sama mir ingnya. Miring pun tungku itu bukan miring ke belakang melainkan miring ke depan, teratur bertemu puncak, sama tingginya; besarnya bisa saja tidak sama, tetapi tingginya tidak dapat tidak sama, kalau tidak sama tingginya takkan dapat diletakkan periuk diatas tungku dapur itu. Itulah sebabnya maka konon tungku nan tiga atau ikatan nan tiga dalam adat budaya masyarakat Karo melambangkan ANAKBERU-SENINA-KALIMBUBU (Tarigan, 1994: 22 ).

Sampai saat ini daliken si telu masih digunakan dalam setiap aspek kehidupan masyarakat Karo modern dengan beberapaperubahan dan pergeseran makna. Jika makna rakut sitelu merupakan pengikat keluarga dalam praktik gotong-royong atau serayadn-aron dalam kelompok maka kini makna itu bergeser menjadi sebuah formalitas kerja yang dilakukan dalam kelompok. Faktor yang sangat besar berpengaruh adalah perubahan sosial akibat mulai menghilangnya batas budaya, hal ini senada dengan pendapat Irwan Abdullah dalam pengamatannya terhadap salah satu faktor redefinisi kebudayaan;

Kedua, batas kebudayaan yang mulai menghilang, suatu proses yang berlangsung akibat faktor mobilitas dan akibat proses sosialisasi yang berubah. Mobilitas yang padat menyebabkan landasan budaya seseorang menjadi sangat berbeda dengan sebelumnya sehingga "budaya asal" mula tidak dikenal dengan baik, kemudian proses sosialisasi yang berlangsung pada landasan kebudayaan yang lain menyebabkan luasnya pengetahuan budaya dan juga hilangnya loyalitas tradisional. Kebudayaan mulai menjadi sesuatu yang dipilih" bukan “diterima”(Abdullah, 2010: 173).

Menjadi sebuah pilihan atas dasar romantisme terhadap jati diri sebagai orang keturunan suku Karo yang tidak mengenal utuh budaya nenek moyang dan hanya mengetahui lewat bahasa lisan. Mencoba untuk menggali nilai tradisional yang 'asli' walaupun tidak memungkinkan karena budaya tradisional sudah berubah dari sisi bentuk, makna, dan pemiliknya. Penerimaan jati diri sebagai orang Karo adalah saat menyandang nama merga/beru, mengetahui silsilah keluarga saat saling bertemu dengan orang Karo yang lain sebagai salah satu bentuk dari ertutur, hal ini pun sudah sangat jarang sekali diajarkan kecuali saat ada pertemuan dengan keluarga besar melalui upacara adat. Generasi muda Karo sering mengalami apa yang disebut dengan 'gagap budaya'. Akibatnya mereka berpaling ke budaya populer.

Sebagai generasi muda yang hidup ditengahtengah kehidupan yang modern dan arus teknologi informasi serta komunikasi yang cepat, pelaku budaya Karo masa kini memungkinkan mengalami persilangan budaya. Segala sesuatu menjadi populer, baik itu genre musik, gaya berpakaian maupun gaya hidup menjadi patokan dalam menjalani hidup sehari-hari. Gencarnya dunia hiburan dalam mengeksploitasi segala sesuatu yang sedang trendy menjadikannya semakin dekat dan melekat pada gaya hidup saat ini. Budaya populer yang menjadi pilihan penulis adalah gaya 'Hip Hop'. Jannis Androutsopoulos (dalam Alim, 2009: 43). dalam Language and the Three Spheres of Hip Hop menuliskan;

"To be sure, Hip Hop's traditional "four elements"- breaking, Djing, rapping, and writing 
- a rely on performance modes that go well beyond language, such as visual representation, sound, movement, and technical manipulation of objects. But more than verbal art, language in Hip Hop is the medium in which artist performances and member identities are contextualized and negociated."

Terjemahan:

Hip Hop yang tradisional memiliki empat elemen dasar-breaking, $D j$, rapping dan writing-menghadirkan pertunjukan melebihi bahasa, berupa pertunjukan visual, bunyi, gerakan, dan manipulasi objek. Sebagai sebuah pertunjukan tidak saja menghadirkan seni verbal, namun sebagai media penyampai akan gagasan yang konstektual dan menghadirkan tawarantawaran baru terhadap perubahan oleh seniman dan kelompok sebagai bagian dari penyampai identitas.

Hip Hop sebagai budaya yang pertama kali berkembang di Amerika Serikat khususnya di dacrah Bronx meluas ke seluruh dunia. Meskipun daya tarik dan perkembangan Hip Hop melintasi batasan budaya dan ras, Hip Hop merupakan fenomena kultural dari kebudayaan AfrikaAmerika yang muncul bersamaan dengan kompleksitas campuran dari pengaruh-pengaruh sosial hibrid (Forman, 2001: 9). Pendapat yang lain mengatakan bahwa Hip Hop selalu menjadi milik minoritas budaya Afrika-Amerika. Tetapi Hip Hop telah menjadi bahasa internasional, sebuah gaya yang menghubungkan dan menunjukkan jati diri banyak generasi muda (Bozza, 2003: 130).

Hip Hop tidak hanya menjadi fenomena namun Hip Hop telah menjadi gaya yang menginspirasi generasi muda untuk menciptakan identitas diri. Seorang seniman Amerika yang menggeluti dunia Hip Hop sebagai breakdancer, seniman grafiti dan rapper mengutarakan pemikiran yang menarik dalam sebuah tulisannyaTowards A Hip-Hop Aesthetic: A Manifesto for the Hip-Hop Arts Movement- tentang Hip Hop yang menjadi wacana baru budaya populer dan mengalami perkembangan serta menjadi bahan pembicaraan di mana Hip Hop mengalami tantangan tidak hanya bermakna sebagai budaya, namun makna Hip Hop sebagai karya seni, karena Hip Hop adalah karya seni (Hoch, 2006: 1). Hip Hop yang merupakan karya seni dipentaskan di dalam sebuah gedung pertunjukan, galeri bahkan di sekolah-sekolah dibandingkan di jalanan atau tempat publik yang selama ini menjadi bagian dari budaya urban.

Melalui pemikiran-pemikiran tersebut penulis memiliki keinginan untuk mewujudkan sebuah pertunjukan teater dengan estetika Hip Hop yang dikolaborasikan dengan budaya Karo sebagai sebuah garapan yang kontemporer. Penulis berharap estetika pertunjukan teater Karo Hip Hop dapat menjadi sebuah tawaran bentuk kreativitas baru dalam dunia panggung teater.

\section{Metode Pelatihan Teater Karo Hip Hop}

Pementasan teater dengan judul KAI Pertunjukan Kontemporer Teater Karo Hip Hop merupakan tawaran kerja kreatif seorang sutradara di antara banyak ragam pementasan teater kontemporer. Mengusung tema "Ambisi Kuasa Berbuah Tragedi”, pilihan seseorang dalam menjani hidup menjadi penting karena mempengaruhi setiap aspek yang terjadi di masa depan. Keinginan manusia yang besar akan kekuasaan telah menyebabkan hubungan bapak dan anak putus, orang-orang disekelilingnya terimbas perbuatan jahat, tidak ada lagi ketenteraman dan tragedi pun terjadi.

Garapan yang sedari awal memang diarahkan mengambil bentuk dari budaya Hip Hop, memberikan tawaran estetika yang relatif baru di dunia seni teater, walaupun tidak menutup kemungkinan seniman lain telah melakukan eksperimen yang sama, tentu saja dengan berbeda sentuhan. Perbedaan ini terletak pada nilai estetika yang terinspirasi oleh budaya Karo. Teater Karo Hip Hop sebagai tawaran dari alternatif tontonan pertunjukan teater kontemporer ingin menjadi bagian dari perkembangan budaya populer di Indonesia.

Penulis melakukan beberapa tahapan untuk menggarap pertunjukan ini, mulai dari proses interpretasi, pelatihan hingga tahap perwujudan. Interpretasi di wilayah penyutradaraan berkaitan dengan analisa naskah, yaitu bagaimana mewujudkan peristiwa dalam pemanggungan. Proses interpretasi adalah bagaimana menganalisis, membuat jabaran tentang tujuan, dan menjelaskan bagaimana peristiwa itu terjadi dan saling terkait (Frerer, 1996: 81). Naskah "KAI" diinterpretasikan penulis dengan gaya pilihan memadukan teater dengan gerakan tari Hip Hop. Unsur cerita 
yang bersumber dari legenda dan daliken si telu diwujudkan dalam sosok Kai dan konflik yang diciptakan tokoh utama yang mempengaruhi tokoh-tokoh lain. Konflik ini terjadi akibat dari sikap yang tidak hormat terhadap kalimbubu, dan sikap ambisius seseorang yang seharusnya menjadi pengayom justru sebaliknya orang tersebut ingin menghancurkan tatanan dan adat istiadat.

Tahap kedua dari metode yang digunakan adalah proses pelatihan. Tujuan dari pelatihan merupakan kegiatan eksplorasi (Cole dalam Frerer, 1996:148). Proses ini adalah proses kerjasama antara sutradara dan aktor. Pelatihan merupakan pula proses pemilihan pemeran, penulis menitikberatkan pada kebutuhan terhadap fleksibilitas, ketahanan, keseimbangan dan kelenturan tubuh pemain. Para pemain harus siap belajar gerakan-gerakan dan postur tubuh yang sering digunakan dalam tarian Hip Hop. Tidak ada aturan yang baku atau cara yang paling tepat untuk menggarap sebuah naskah atau menempatkan pemain dalam pengadeganan; karena banyak sekali kemungkinan-kemungkinannya (Frerer, 1996: 151). Seorang pemain bebas mencoba mengeksplorasi ruang permainan, bermain aksi reaksi dengan lawan main, mencari chemistry dalam permainan penempatan tubuh dalam jarak jauh-dekat, lembut-keras, arah hadap dan langkah kaki cepat-lambat. Gerak menjadi identifikasi karakter masing-masing tokoh. Beberapa jenis gerak Hip Hop menjadi pilihan antara lain; krumping, wacking, breaker, rocking, tower, jerk, dan tuting.

Untuk gerak tari Karo sendiri ada gerak tangan kiri naik, gerak tangan kanan ke bawah melambangkan tengah rukur, yaitu maknanya selalu menimbang segala sesuatunya dalam bertindak; gerakan tangan kanan ke atas, gerakan tangan kiri ke bawah melambangkan sisampatsampaten, yang artinya saling tolong menolong dan saling membantu; gerakan tangan kiri ke kanan ke depan melambangkan ise pe la banci ndeher adi lenga si oraten, yang artinya siapa pun tidak boleh dekat kalau belum mengetahui hubungan kekerabatan, ataupun tidak kenal maka tidak sayang. Dasar dari gerak tari tradisi dan Hip Hop kemudian di respon oleh pemain dalam melakukan akting. Gerak telah menjadi bahasa baru dalam berkomunikasi dan menyampaikan pesan serta emosi. Di bagian inilah tantangan keaktoran bagi para pendukung pentas "Kai" yang belum terbiasa dengan gerak sebagai bahasa simbol dan sebagai presentasi dari pergolakan pikir, serta daya ungkap untuk menceritakan perasaan. Penulis juga melakukan eksplorasi penempatan area permainan dengan menginspirasi bentuk-bentuk geometris yang sering digunakan dalam bentuk ukiran yang ada di rumah adat Karo. Penulis mencoba melihat efek dari bentuk geometris ini di atas panggung, karena dari sudut perspektif estetis penulis menganggap bahwa bentukbentuk ini memungkinkan untuk dihadirkan ke atas panggung jenis panggung terbuka, di mana penonton dapat melihat permainan aktor dari tiga sisi sudut pandang.

Tahap ketiga yaitu, perwujudan. Untuk mewujudkan pertunjukan ini penulis menganalisis dan menciptakan bentuk dari segi elemen dasar Hip Hop, elemen budaya Karo dan spektakel.

\section{Elemen Dasar Hip Hop}

\section{Grafiti}

Grafiti merupakan sebuah bentuk dari ekspresi diri melalui tulisan yang ditorehkan di dinding. Dunia arkeologi pertama kali menggunakan istilah "grafiti" untuk menggambarkan sistem komunikasi dan ekspresi yang diungkapkan melalui tulisan, gambar, dan menggosok pada permukaan dinding (Price, 2006: 28). Penggunaan grafiti dalam pementasan Kai merupakan bagian dari penataan set panggung. Tulisan yang muncul adalah huruf KA I, ketiga huruf ini menyimbolkan pemberontakan tokoh Kai terhadap masyarakat Kuta, otoritas yang berlaku di tengah masyarakat. Tulisan tersebut merupakan upaya Kai untuk unjuk gigi mengatakan bahwa tempat tersebut telah ditandai menjadi hak miliknya. Siapa pun yang berdiri di atas propertinya secara tidak langsung orang tersebut berada di bawah kekuasaannya. 


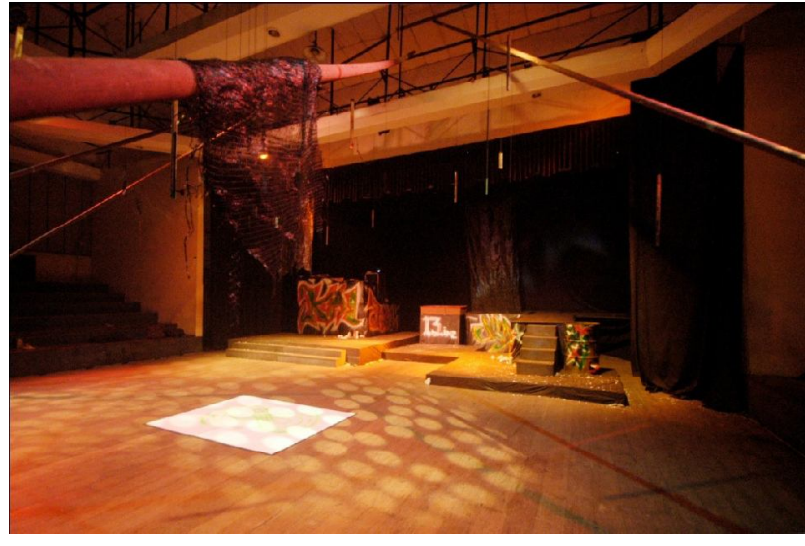

Gambar 1. Set yang penuh dengan grafiti, terdapat tulisan KAI di sudut kanan panggung

(Foto: Greg Agung, 2012)

\section{Rap}

Gaya Rap adalah gaya menyanayi yang digunakan dalam seni bercerita dan hadir di dalam situasi peperangan, kerusuhan. Gaya Rap digunakan juga untuk berbicara tentang panggilan hati dan bagaimana menjawab panggilan tersebut (Hoch, 2006:3). Tokoh yang membawakan dialog dengan menyanyi Rap adalah Sebayang dan Rapper yang bertindak sebagai narator.

Sebayang : sering ku dengar

Sebuah kota yang hijau

Elok subur

Membuat iri hati banyak orang

Di atas bukit

Bisa kau lihat

Berderet-deret tanah menghijau

Buah segar, lagi ranum

Sungai yang berbual-bual airnya

Tidak ada kesusahan

Tidak ada kekeringan

Rapper : La erngadi-ngadi ibas pengarapen

Peratenna si nguasai

Si dem alu peraten

Dungna si jadi jelma si perate-ate

Aku.. aku.. aku.. la lit sideban

Pentang ngenen sideban

La mpediateken kai silit i lebe-lebe matana

Alu metikken jari tan

Ngarapken kerina takal nungkuk

Jari tan kudatas

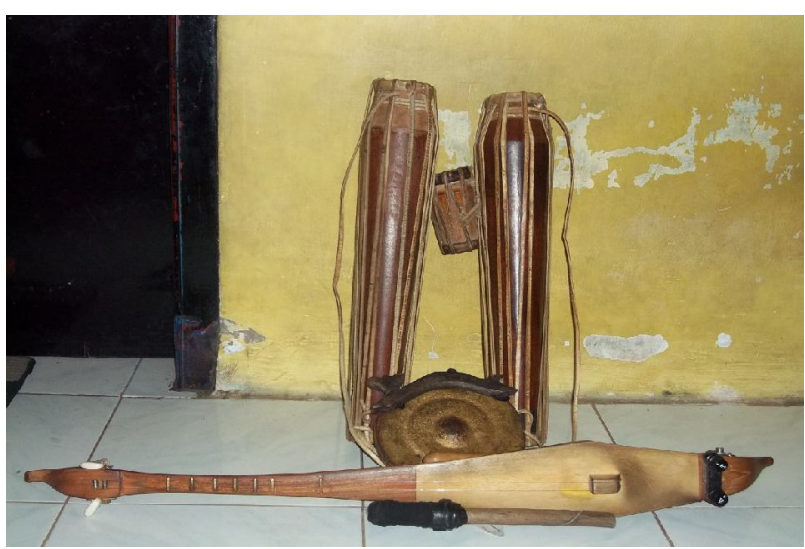

Gambar 2. Kulcapi (bawah), penganak, gendang singanak (kanan), gendang perindungan

(Foto: Silvia AP, 2012)

\section{DJ-ing}

DJ-ing adalah suara musik melalui media piringan disket yang dapat diputar, digesekkan, musik yang melonjak-lonjak dan di campur adukkan/mixing, tampil langsung dihadapan penonton. DJ akan di tempatkan di bagian belakang panggung dengan live performance memainkan komposisi musik yang telah di rekam sebelumnya namun memungkinkan untuk berimprovisasi. Untuk pementasan ini, penulis memasukkan bunyi musik dari instrumen tradisional Karo yaitu, kulcapi, penganak dan gendang perindungen. Hasil rekaman musik dari instrumen Karo dimasukkan komputer secara digital dan di mixing dengan musik digital yang sudah ada.

\section{B-boying}

B-boying tenar disebut dengan breakdance tarian ini dipengaruhi aliran musik funk dan disco, gerakan-gerakan breakdance dipengaruhi gerakan tarian tradisi Afrika Barat, Puerto Rico, Brasil, Kuba dan Rep. Dominika (ibid, 3). Tarian ini akan menjadi bagian dari adegan pertempuran, loncatan-loncatan peristiwa dari narasi sang rapper. Breakdance sangat penting karena dapat menceriakan dan menghidupkan suasana yang terlanjur tinggi, sehingga penonton dapat bernafas dan menikmati pertunjukan dengan tangga dramatis yang stabil. 


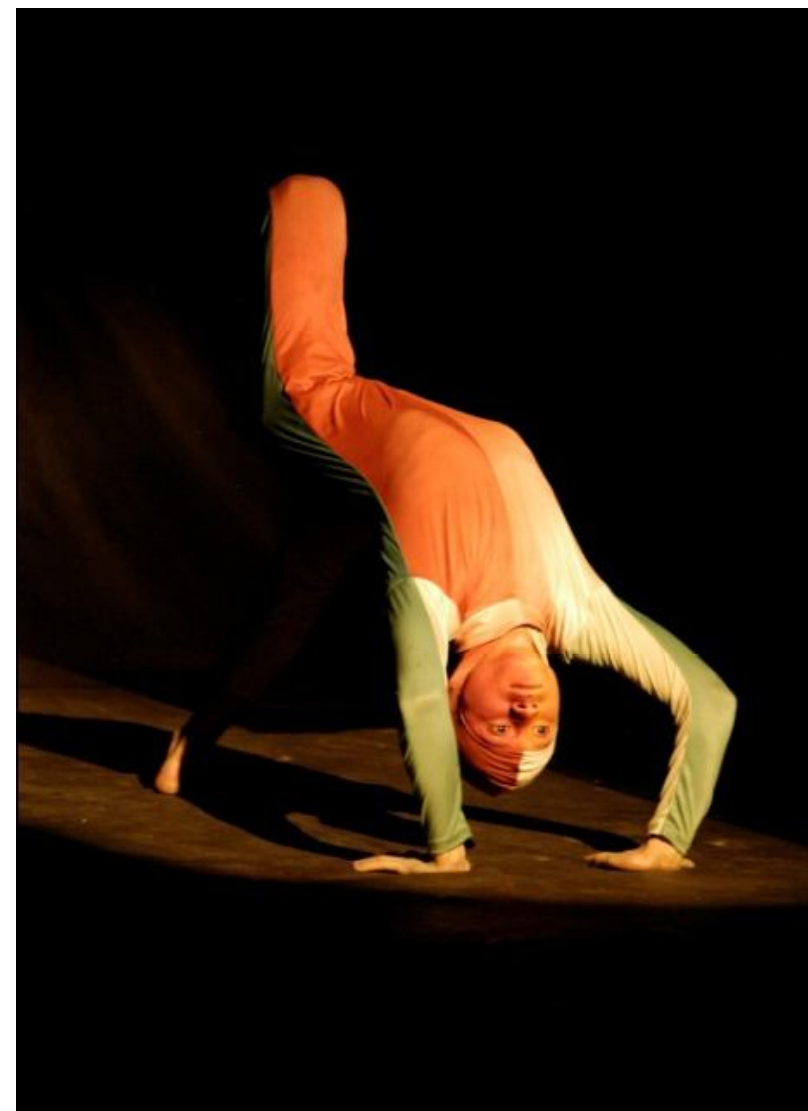

Gambar 3 Gerakan Matang terinspirasi dari gerak akrobatik dan breakdance

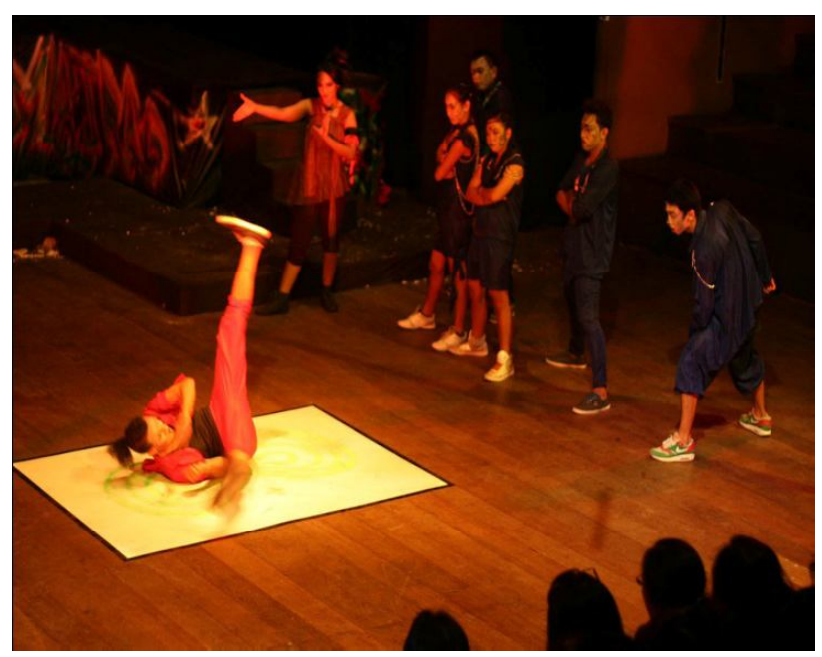

Gambar 4. Salah seorang breaker dalam adegan perang menggunakan gerakan breakdance (Foto: Greg Agung, 2012)

\section{Elemen Budaya Karo}

\section{Merga Silima}

Suatu masyarakat dikatakan adajika masyarakat itu dapat menunjukkan identitasnya yang berbeda dengan masyarakat lainnya (Peranginangin, 2004: 121). Oleh karena itu masyarakat Karo memiliki tatanan kehidupan bermasyarakat yang melekat, unik, dan memiliki sistemnya sendiri. Orang Karo mengenal sistem Merga Silima yang mengacu kepada lima marga induk, yaitu: 1) Karo-karo, 2) Ginting, 3) Tarigan, 4) Sembiring, dan 5) Peranginangin. Untuk mewakili bagian ini dalam proses penciptaan adalah penggunaan nama Charo yang merujuk pada marga Karo-karo, seorang anak perempuan yang memiliki beru Karo-karo otomatis bapaknya juga bermarga Karo-karo, di dalam naskah merujuk pada tokoh Kai. Tokoh ini mengambil posisi yang bertentangan dengan norma pada umumnyakarena seseorang sebenarnya pantang di panggil nama depannya. Berikutnya ada tokoh yang bernama Nande Bugan, nama Bugan merujuk pada merga Sembiring, kemudian ada tokoh yang lain bernama Sebayang, yang merupakan subklan dari merga Peranginangin dan Nangin dari singkatan Peranginangin.

\section{Daliken Si Telu/Rakut Si Telu}

Mengenaihubungan kekerabatan digambarkan secara tersirat. Nande Bugan merupakan kalimbubu Kai akibat dari bersaudara dengan istri Kai dari pihak ayah, berarti Charo adalah keponakan dari Nande Bugan. Peran sebagai kalimbubu memberikan keistimewaan kepada Nande Bugan sebagai seseorang yang harus di dengar perkataan dan pemikirannya oleh Kai. Sikap tidak taat dan tidak mengindahkan terhadap kalimbubu menunjukkan sikap tidak hormat, menyakiti perasaan kalimbubu sebagai presentasi dibata ni idah/tuhan yang nampak. Sedangkan Sebayang digambarkan merupakan seseorang yang bermarga Peranginangin bere-bere Karo, sehingga Sebayang merupakan impal dari Charo. Kedudukan sebagai impal memberikan peluang bagi Sebayang untuk dapat mendekati Charo bahkan menikahinya.

\section{Seni Ukir}

Budaya Karo juga meliputi seni ukir atau ornamen yang ada pada bangunan rumah adat, peralatan dapur, alat musik, dan pakaian adat. Untuk penciptaan kali ini beberapa bentuk diadopsi dan direpresentasikan dalam visual artistik di bagian set bangunan, tata rias para pendukung, dan kostum yang digunakan. 


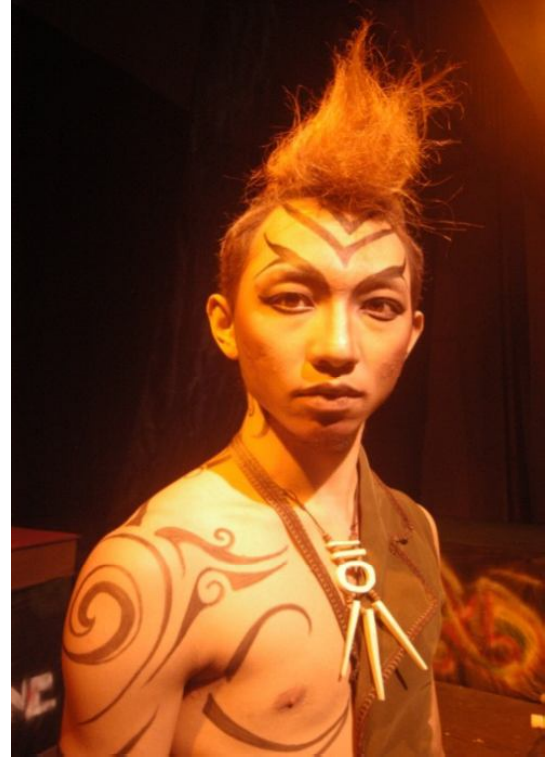

Gambar 5. Tata rias tokoh Kai. Gambar pada tubuh mengadopsi dari motif ornamen Lukisen Bulung Binara. (Foto: Greg Agung, 2012)

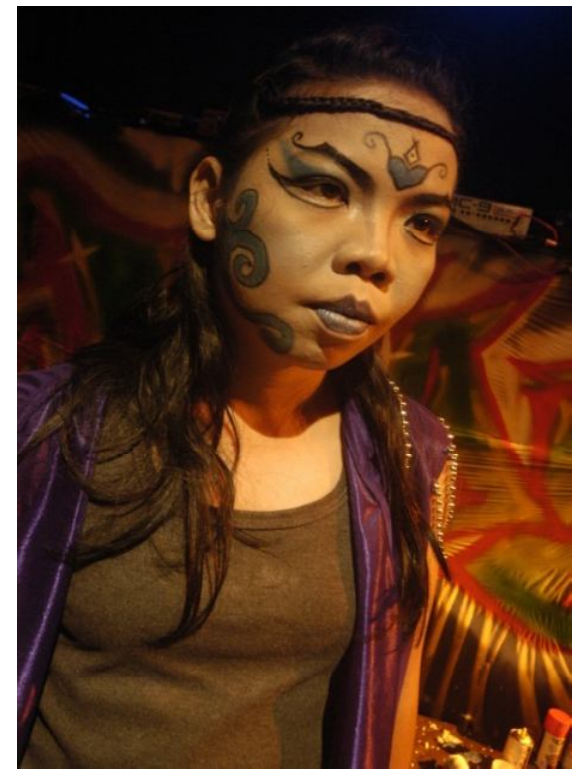

Gambar 6. Motif yang ada di dahi adalah ornamen Pucuk Tenggiang, sedangkan pada pipi adalah ragam hias Taruk-taruk. (Foto: Greg Agung)

\section{Bahasa dan Seni Sastra}

Sastra lisan pada masyarakat Karo ialah tabas, pantun, perumpamaan, turi-turin, cakap lumat, bilang-bilang, ndung-ndungen dan ermangmang. Pilihan penciptaan ini adalah pada sastra lisan tabas dan turi-turin sebagai media penyampai kepada penonton. Merujuk pada tulisan Tridah Bangun;

Tabas atau mantra adalah untuk para "guru si baso"(dukun) dan masyarakat awan jarang mengetahuinya. Umumnya tabas digunakan untuk mengobati orang sakit, upacara pemanggilan roh, dan lain sebagainya. Sedangkan turi-turin atau cerita adalah berbentuk prosa mengenai berbagai hal seperti kesedihan, kesaktian, asal usul kampung, hewan, legenda dan lain-lain (Bangun: 1986, 66).

Tabas digunakan oleh Kai saat memantrai Karo dan masyarakat Kuta, hal ini terlihat dalam dialog:

Kai : kemudaan yang berseri tidak akan hilang

Kecantikan akan membalut tak lekang waktu

Waktu akan bergulir dan kesadaran hilang

Angin dari timur, cahaya dari selatan

Barat dan utara tetaplah bungkam

Biarlah lingkaran melingkupi sampai saatnya ikatan putus oleh api

Darah dengan darah menyatu maka musnahlah kutuk

Sedangkan turi-turin diwakili oleh sosok Rapper dalam dialog-dialognya di adegan 3 yang menceritakan tentang kondisi Kuta dan bagaimana seorang guru simbelin/maha guru yang menyebabkan kehancuran di Kuta. Cerita berikutnya ada pada adegan 8 yang mengisahkan sakit hati Charo mendengar perkataan Kai yang menginginkan kematiannya dan sikap Charo terhadap bapaknya.

\section{Seni Tari}

Seni Tari Karo di bagi menjadi tiga kategori, yaitu: tari kepercayaan, tari adat dan tari mudamudi (Bangun, 2004: 62). Tari kepercayaan dalam masyarakat Karo biasanya dilakukan oleh seorang guru/dukun berdasarkan kepercayaan animisme-dinamisme (ibid,63). Presentasi tari kepercayaan dilakukan oleh Kai dan Nande Bugan sebagai seseorang yang memiliki kemampuan lebih dibandingkan warga Kuta. Pilihan gerak tari masing-masing tokoh sangat berbeda. Kai dengan gerak-gerak krumping dan Nande Bugan dengan gerak tangan tari tradisi Karo. 

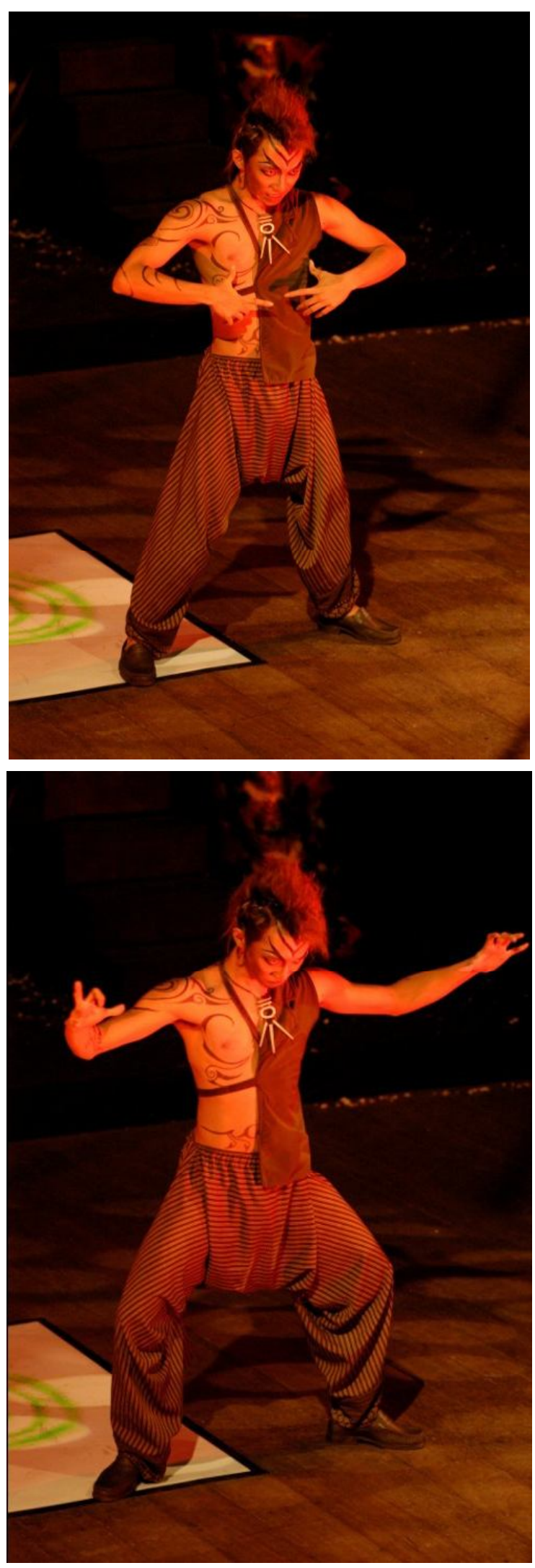

Gambar 7\&8. Gerakan Kai dalam membaca mantramantra yang merupakan presentasi tari kepercayaan dengan gerakan krumping.

(Foto: Greg Agung, 2012)

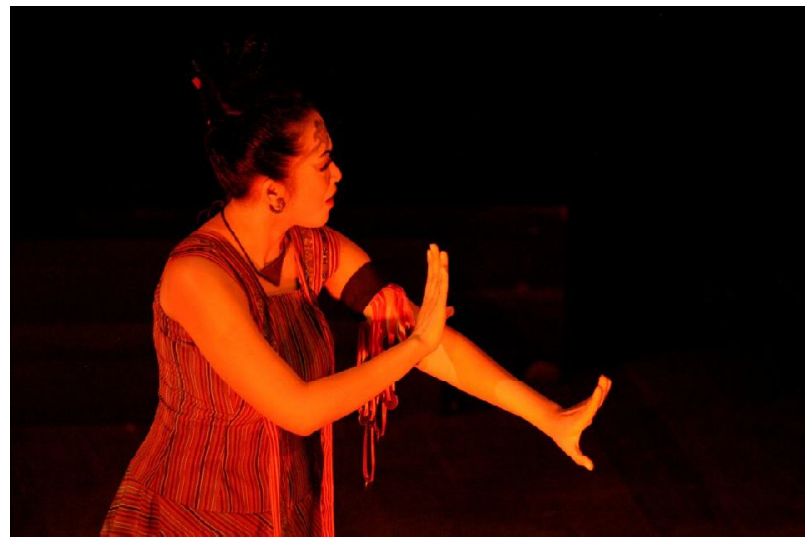

Gambar 9. Gerakan Nande Bugan presentasi tari kepercayaan dengan gerakan tangan tarian Karo. (Foto: Greg Agung)

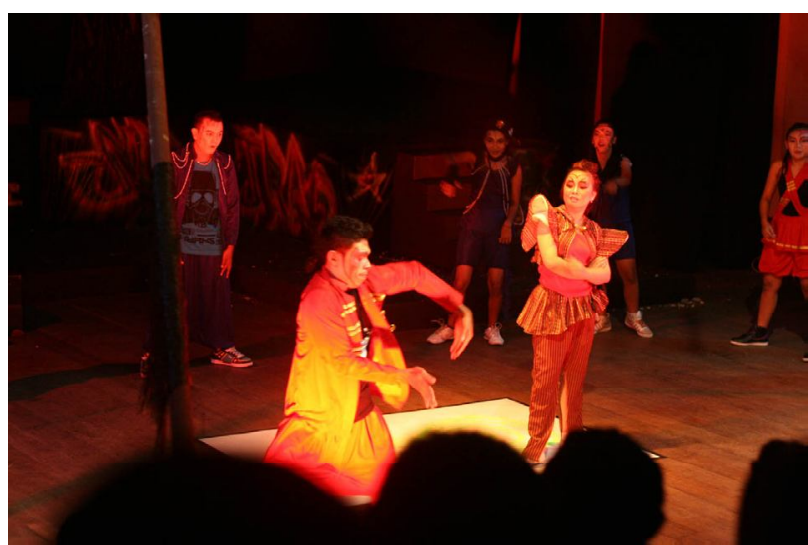

Gambar 10. Tarian muda-mudi dengan tarian berpasangan. (Foto: ibid)

Kemudian presentasi tari muda-mudi dalam penggarapan ini di bawa ke dalam bentuk gerakan freestyle dengan nuansa Hip Hop mulai dari gerakan jerk, girlie, tower, krumping, dan lain sebagainya. Tarian ini akan muncul di pembuka adegan untuk menggambarkan kegairahan anak muda, suasana yang ceria, membawa penonton ke dunia estetika Hip Hop dengan alunan musik yang penuh dengan beat-beatcepat melalui alunan musik yang di putar oleh DJ.

\section{Spektakel Teater Karo Hip Hop}

Pertunjukan teater tidak lengkap jika tidak menghadirkan spektakel yang dapat menyedot perhatian penonton melalui artistik visual peristiwa di atas panggung. Melalui spektakel dapat tercipta simbol-simbol yang baru dan bahasa ungkap yang berbeda. Yudiaryani (2002:364) menjabarkan tentang spektakel atau mise en scène sebagai berikut: 
1) Spektakel adalah gerakan atau tindakan fisik seorang tokoh yang berlangsung di atas panggung. Spektakel dalam hal ini memiliki unsur-unsur visual, yaitu skeneri, kostum, cahaya, rias, gerak pantomim aktor.

2) Spektakel digunakan aktor untuk menyampaikan pikiran, perasaan, dan watak tokoh. Spektakel digunakan pula oleh sutradara untuk menyusun tindakan secara fisik dan akting bisnis tokoh, keluar masuk aktor, pengelompokan aktor, memilih kostum dan rias, menilih ruang panggung sesuai dengan penafsiran naskah.

3) Spektakel adalah ruang visual yang dapat

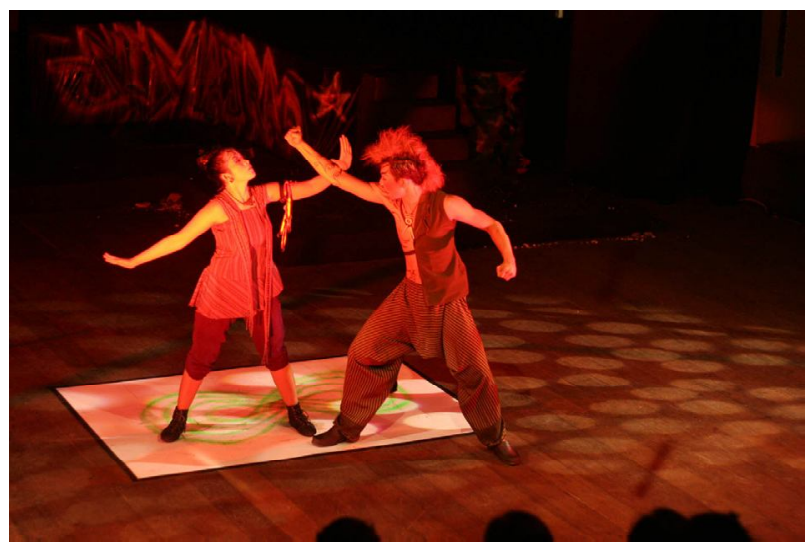

Gambar 11. Adegan adu kekuatan antara Kai dan Nande Bugan. (Foto: Greg Agung)

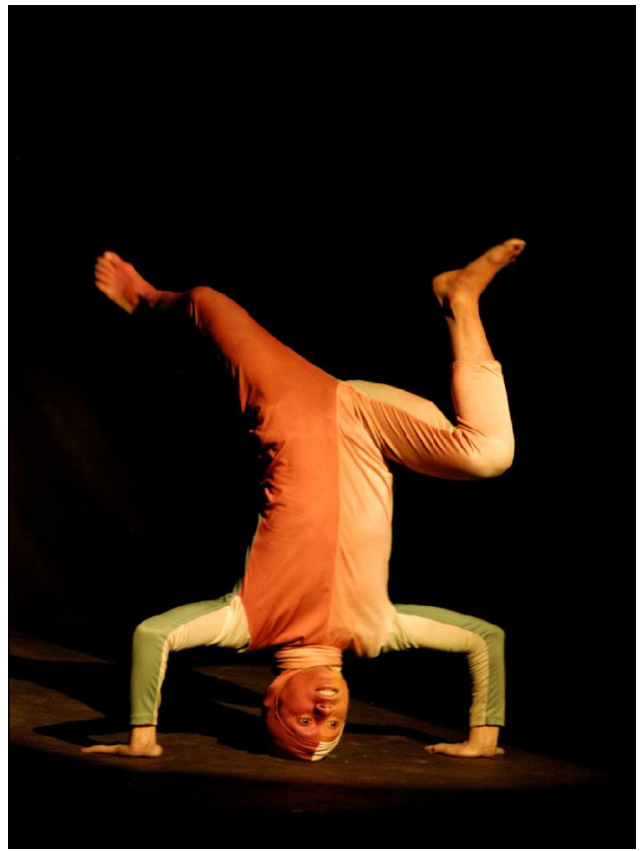

Gambar 12. Adegan Matang dengan gaya akrobatik di atas level untuk menunjukkan sosok magis yang tinggal di dunia roh. (Foto: Greg Agung) disimbolkan melalui suara atau unsur pemanggungan lainnya.

4) Spektakel dapat digunakan untuk meyakinkan tindakan tokoh melalui penempatan skeneri, tata lampu, permainan aktor, tata kostum yang tepat.

5) Spektakel dapat membantu diksi mengungkapkan cerita. Spektakel dapat lebih meyakinkan dibanding dengan kata-kata, karena dibantu oleh penyutradaraan, keaktoran, dan penataan artistik.

Bebarapa spektakel yang di garap dalam pertunjukan ini diwujudkan melalui gambargambar berikut ini;

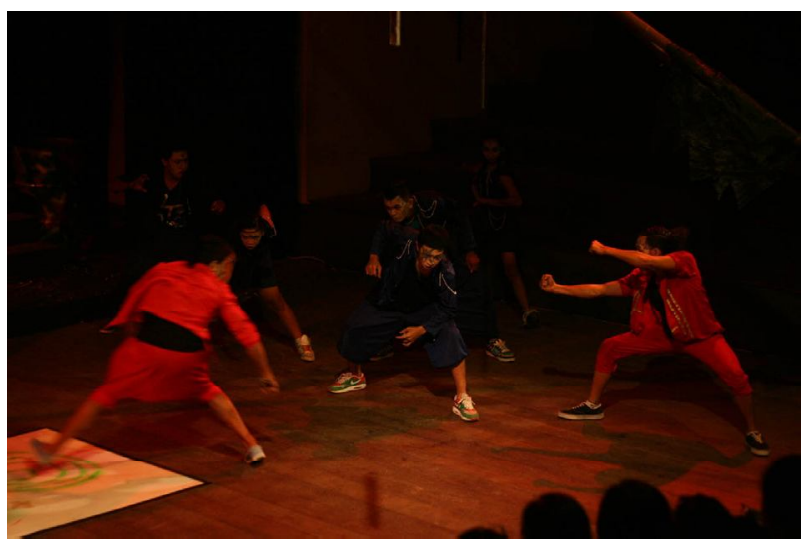

Gambar 13. Adegan pertempuran antara kelompok Nande Bugan (biru) dengan kelompok Kai (merah).

(Foto: Greg Agung, 2012)

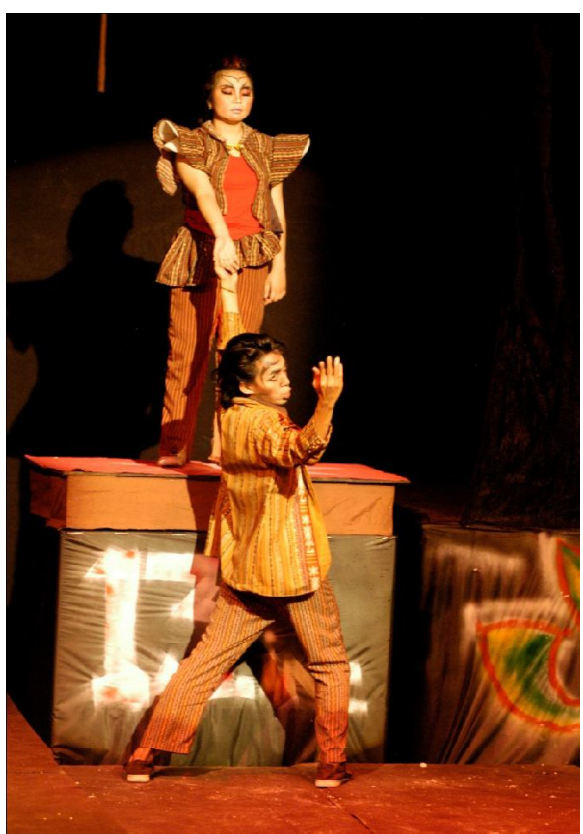

Gambar 14. Adegan Sebayang menghidupkan Charo yang tertidur dalam keabadian dengan mantra-mantra. (Foto: Greg Agung) 


\section{Penutup}

Proses penciptaan Teater Karo Hip Hop KAI sebagai pertunjukan Kontemporer mengalami proses transformasi bentuk yang kaya dari awal mula pelatihan. Penulis melakukan pelatihan dengan eksperimen yang diawali dengan mempertunjukkan sebuah fragmen. Bermula dari fragmen, penulis mulai menyempurnakan bentuk dari memperkaya motif-motif gerak Hip Hop dan gerak tradisi, musik yang awalnya hanya diiringi bunyi musik tradisi mulai ditambah dengan musik digital yang dimainkan oleh $\mathrm{Dj}$, sehingga lebih menunjukkan identitas Hip Hop. Pilihan kostum yang lebih berwarna-warni dan modelnya yang trendy tapi tanpa mengurangi aspek fungsi memudahkan pergerakan para tokoh ketika menari dan akting. Menghadirkan spektakel adegan per adegan yang menimbulkan beragam suasana melalui komposisi permainan, tata cahaya, dialog dan gerakan aksi reaksi para tokoh. Pertunjukan ini mampu memberikan tawaran estetika tersendiri di panggung pertunjukan teater kontemporer.

\section{Kepustakaan}

Abdullah, Irwan. 2010. Konstruksi dan Reproduksi Kebudayaan. Yogyakarta: Pustaka Pelajar.
Androutsopoulos, Janis. 2009. Global Linguistic Flows: Hip Hop Cultures, Youth Identities, and the politics of language. New York: Routledge.

Bangun, Tridah. 1986. Manusia Batak Karo. Jakarta: Inti Idayu Press.

Bozza, A. 2003. Whatever You Say I am: The life and times of Eminem. London: Bantam.

Frerer, Lloyd Anton. 1996. Directing for the Stage. USA: NTC Publishing Group.

Hoch, Danny. 2006. Jurnal Towards A Hip-Hop Aesthetic: A Manifesto for the Hip-Hop Arts Movement. New York: Routledge.

Peranginangin, Martin L. 2004. Orang Karo Diantara Orang Batak. Jakarta: Pustaka Sora Mido.

Price, Emmett George. 2006. Hip Hop Culture. California: ABC-CLIO.

Tarigan, Henry Guntur. 1994. Antusen Bilangen ibas Kalak Karo, Makna Bilangan pada Masyarakat Karo. Bandung: FPBS IKIP Bandung.

Yudiaryani. 2002. Panggung Teater Dunia Perkembangan dan Perubahan Konvensi. Yogyakarta: Pustaka Gondosuli. 